\title{
Chapter 14 \\ Internal Solitary Waves System in the Mozambique Channel
}

\author{
Jorge M. Magalhaes, José C. B. da Silva and Adrian L. New
}

\begin{abstract}
Satellite images of the Mozambique Channel (MC), collected by Synthetic Aperture Radars (SARs) from the Envisat and European Remote Sensing (ERS) satellites, reveal sea surface signatures of oceanic Internal Solitary Waves (ISWs). The MC has been expected to be a major hotspot for the generation of Internal Tides (ITs) in the ocean. New results now show that the Sofala bank (or shelf, located near $20^{\circ} \mathrm{S}, 36^{\circ} \mathrm{E}$ ) is indeed a strong and previously unknown source for the generation of ITs and ISWs. The hotspot region is located between 20 and $21^{\circ} \mathrm{S}$, where the barotropic tidal forcing and tidal transports are highest in the area, due to the particular nature of the bathymetry there. Two distinct types of ISWs are observed to travel offshore, away from the shelf-break, and their possible generation mechanisms are discussed. Mode 2 ISWs propagating in MC are also observed in SAR imagery. It is discussed that they may be generated by a tidal beam impinging the thermocline from below, in a similar process to some of the Mode 1 ISWs generated off the Sofala bank. ISW refraction patterns, often observed in SAR imagery in MC are presented, and a particular example is shown where ISWs and eddy-like features are seen to interact. The influence of these rotating features in the refraction patterns is briefly discussed. Finally, it is shown that large-scale atmospheric gravity waves of solitary-like form are also frequently observed in the region, and thus care must be taken when discriminating oceanic and atmospheric ISW signatures in SAR images, if a correct interpretation is to be made.
\end{abstract}

J. M. Magalhaes $(\bowtie) \cdot$ J. C. B. da Silva

Department of Geosciences, Environment, and Spatial Planning,

Interdisciplinary Centre of Marine and Environmental Research, CIMAR,

Porto, Portugal

e-mail: jmagalhaes@fc.ul.pt

Also at: Faculty of Sciences, University of Porto, Porto, Portugal

A. L. New

Marine Systems Modelling Group, National Oceanography Centre,

Southampton, Southampton, UK 


\subsection{Introduction}

Internal Waves (IWs) are an important factor in several processes within geophysical fluid dynamics. They are ubiquitous features in the oceans and in the atmosphere, which can exist in a wide variety of time and space scales, and owe their existence to the vertical density stratification that characterizes both mediums.

In the ocean, tidal flow over irregular bottom topography can force vertical motions at the tidal frequency and generate IWs of tidal period, which can then propagate along the thermocline and are often referred to as Internal Tides (ITs). ITs can steepen and generate IWs of shorter period that are usually termed Internal Solitary Waves (ISWs). The term 'solitary' is used since they tend to occur in individual packets (usually trapped in the troughs of the IT), and have often been identified with the soliton solutions of nonlinear wave theory. In the atmosphere, these short-scale waves that are usually highly nonlinear, can also be observed to propagate in the lower troposphere, and are often accompanied by roll-cloud formations that resemble the packet-like structure of their oceanic counter-part. Their origin can be attributed to various generation mechanisms, often involving convection, wind-shear, gravity currents and different air mass collisions. In summary, any atmospheric process leading to the displacement of density surfaces can be a potential source of atmospheric IWs, providing that suitable propagation conditions are previously met.

During the last few decades remote sensing has played a key role, in providing the scientific community with an increasing number of IW observations (both of oceanic and atmospheric nature). Imaging sensors such as Synthetic Aperture Radars (SARs), as well as visible and near-infrared spectrometers, have proved to be particularly useful in providing new and valuable insights into these waves' physical characteristics. These new measuring capabilities boosted the number of observations, and led to several studies that indicated that the phenomenon is in fact much more frequent than previously thought (see e.g. Jackson 2007; Jackson et al. 2012; da Silva and Magalhaes 2009; Magalhaes et al. 2011). SARs in particular have proved very useful in revealing the two dimensional structure of IWs, as well as their spatial and temporal distributions. It is well known that both oceanic and atmospheric IWs are capable of producing roughness patterns on the ocean surface. Therefore, they can generate recognizable signatures in radar images. The oceanic roughness patterns are a result of either hydrodynamic modulation of Bragg waves by surface current gradients or wave damping due to surface films (Alpers 1985; da Silva et al. 1998). Similarly, the atmospheric IW signatures are a consequence of wind stress variability introduced by the disturbed wind velocity field associated with wave propagation (Alpers and Stilke 1996). SAR imagery has also been playing a key role in identifying and characterizing several IW hotspots, as well as in providing valuable insights into the generation mechanisms (see e.g. New and da Silva 2002; Vlasenko and Alpers 2005; Nash and Moum 2005; da Silva and Helfrich 2008; da Silva and Magalhaes 2009; da Silva et al. 2009, 2011; Magalhaes et al. 2011).

IWs can play an important role in several dynamic aspects and in a wide variety of geophysical processes. As already mentioned above, a more special case of these 
waves are the solitary waves of finite amplitude and permanent form, which owe their existence to a delicate balance between linear wave dispersion and nonlinear wave steepening. These are usually found in rank-order packets (a consequence of their speed being an increasing function of amplitude) and they have been observed to travel for considerable amounts of distance without significant changes in form. In turn, this is a clear indication that these waves can in fact be responsible for transferring considerable amounts of energy throughout large distances, which is one of the main reasons why they are so important in the dynamics of the coastal oceans and in the lower troposphere.

On the one hand, ISWs in the ocean have been proved to significantly contribute to ocean mixing, either during breaking processes in their final stages of propagation, or due to their highly turbulent character as they propagate along the pycnocline (Pinkel 2000; Moum et al. 2003; van Haren et al. 2005; Lamb and Farmer 2011). In fact, recent studies have shown that IWs contribute considerably to shelf dynamics in terms of vertical heat fluxes and ocean-shelf mass transports (Shroyer et al. 2010a, 2010b). Mixing due to IWs has also been shown to be important from a biological point of view. Several studies have shown that the dissipation of ISWs may constitute a primary mixing mechanism, and that it may be sufficient to induce strong upward fluxes of nutrients across the thermocline and produce bursts of primary production (see e.g. Sandstrom and Elliott 1984; Pingree et al. 1986). Da Silva et al. (2002) also suggested that enhanced primary production, could simply occur due to the increase and decrease in available light experienced by phytoplankton, during up and downward advection induced by IWs.

On the other hand, atmospheric IWs of solitary form-sometimes also termed Atmospheric Gravity Waves (AGWs) - have been shown to constitute a serious hazard to aircrafts operating at low altitudes and small speeds (see e.g. Christie and Muirhead 1983; Bedard et al. 1986). Some large-scale AGWs may also have a significant role in establishing low-level circulation and determining the vertical structure of wind, temperature and moisture. They can even modify and trigger convective motions and induce significant rain (Reeder et al. 1995). Their ability to transfer energy and momentum (together with the fact that they propagate for several hundreds of kilometres) makes them an important topic for research, especially since their influence can also extend into weather forecast and climate models.

Furthermore, ISWs can sometimes occur in regions where both mediums (ocean and atmosphere) can support simultaneous propagation. In these cases, care should be taken to avoid miss-interpretation. It is also important to recognize that atmospheric internal waves may not always be associated with cloud structures, since the ascending branches of the waves may not find the necessary conditions (high moisture in the atmosphere) for condensation to occur (see e.g. Crook 1986). In this case, there are no guaranteed methods to discriminate between oceanic and atmospheric ISW sea surface signatures in SAR images. However, recent research based on solitary wave and radar imaging theory has provided useful criteria (sometimes with complementary information on the ocean and atmosphere) to help in the distinguishing process (see Alpers and Huang 2011). 


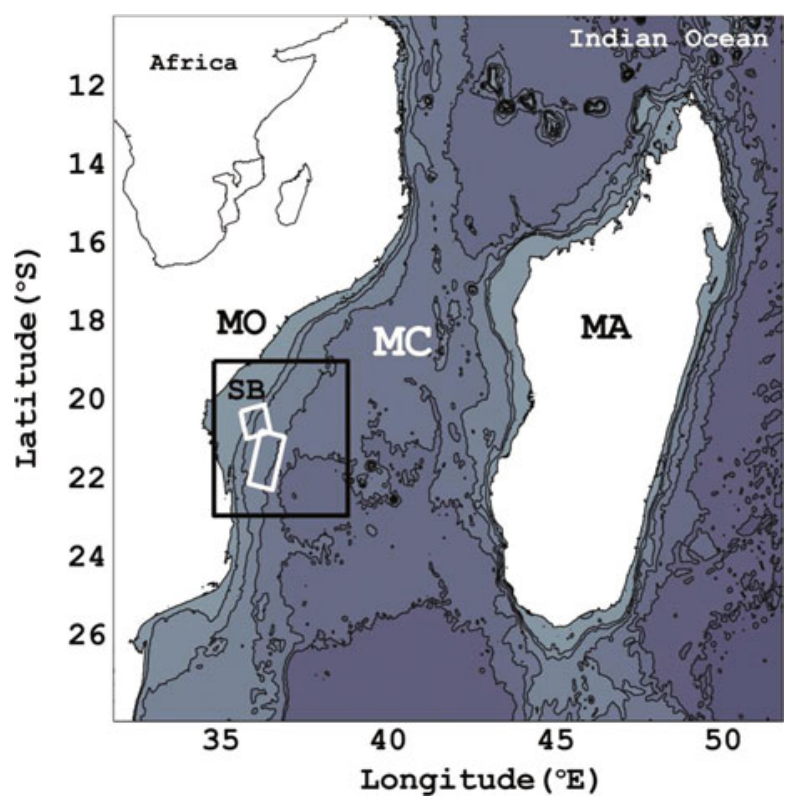

Fig. 14.1 Detailed bathymetry and location of the Mozambique Channel (labelled $M C$ ) in the southwest Indian Ocean. The labels $M O$ and $M A$ stand for Mozambique and Madagascar, respectively, and a reference location for the Sofala Bank is labelled $S B$. The inset in the top-left corner shows the locations of Mozambique and Madagascar in relation to the African continent. White areas represent land and black contours with grey areas mark isobaths for 200, 1,000, 2,000, 3,000 and $4,000 \mathrm{~m}$. The white rectangular frames delineate the area surveyed in the SAR images shown in Figs. 14.2 and 14.3. The black rectangular frame is shown for reference and outlines the detailed area in Figs. 14.4 and 14.5

The Mozambique Channel (MC), sometimes also referred as the Strait of Madagascar, is a relative narrow passage centred at $20^{\circ} \mathrm{S}$ between the African continent (i.e. Mozambique) and the island of Madagascar (see Fig. 14.1). It extends approximately from the northeast to the southwest for more than $1,500 \mathrm{~km}$. The width of the channel is approximately $400 \mathrm{~km}$ in the narrowest passage, while at $20^{\circ} \mathrm{S}$ it reaches a maximum width of about $1,000 \mathrm{~km}$. The continental shelves on both sides are generally narrow, and are confined by supercritical continental slopes. However, near $20^{\circ} \mathrm{S}$ the shelf extends much further into the open ocean, for more than $100 \mathrm{~km}$ (in the Sofala Bank region, see Fig. 14.1 for location) and it is there that the tidal currents are the largest in MC.

This region is a privileged site for the observation of IWs both in the ocean and in the atmosphere. The existence of oceanic IWs is in agreement with Baines (1982), who estimated tidal energy fluxes from several shelf regions of the world's oceans, and showed that MC was among the 12 most energetic regions for IT generation. Here, the (semidiurnal) barotropic tidal ranges are over $7 \mathrm{~m}$, and the barotropic currents typically exceed $0.50 \mathrm{~ms}^{-1}$ at spring-tides, with significant spring-neap 
variability. The shelf slope is also supercritical with respect to the $\mathrm{M}_{2}$ barotropic tide (also known as the principal lunar semi-diurnal tide, with a period of $12.42 \mathrm{~h}$ ), allowing the existence of critical regions for IT generation at the shelf break. Also noteworthy, is the fact that the flow in MC is influenced by large, southward propagating eddies, which feed their waters into the Agulhas Current system, and therefore constitute a major contribution to the overall flow within the channel.

\subsection{Oceanic ISWs}

\subsubsection{Introduction}

Internal tidal energy generated at the shelf-break may radiate away either horizontally in the form of interfacial ITs that propagate along the thermocline, or as internal tidal beams that propagate into the deep stratified ocean below. Therefore, large interfacial ITs may form in the thermocline directly above the shelf break and evolve (through nonlinear processes) to higher-frequency ISWs packets. Another possibility is that the IT energy, which propagates downward into the deep ocean, may give rise to a second generation mechanism known as "local generation" (New and Pingree 1992; Gerkema 2001; New and da Silva 2002; Akylas et al. 2007; Grisouard et al. 2011; Mercier et al. 2012). Here, a beam (or ray) of IT energy is generated at "critical" slope regions of the shelf-break where the bottom topographic slope matches the slope of the ray paths, and propagates at an angle $(\theta)$ to the horizontal into the deep ocean interior (see Eq. 14.1) where $\sigma$ is the tidal frequency, $f$ the Coriolis parameter and $N$ the buoyancy frequency). These rays reflect from the seafloor (Pingree and New 1989, 1991), and interact with the thermocline from below, causing large IT oscillations there, and "locally" generating ISWs (far from the shelf-break where the beam is initially generated). We will show clear evidence (based on remote sensing SAR images and modelling results) that both generation mechanisms are at work in $\mathrm{MC}$, which means that there are waves being formed directly at the shelf break, and further into the open ocean through local generation.

$$
\tan (\theta)= \pm\left(\frac{\sigma^{2}-f^{2}}{N^{2}-\sigma^{2}}\right)^{1 / 2}
$$

This hypothesis was originally proposed to explain some ISW observations in the northern Bay of Biscay, where it was studied for the first time, and where SAR imagery helped to clearly distinguish a bimodal distribution of ISWs. This distribution results from the direct generation mechanism near the shelf-break and from the local generation processes taking place some $150 \mathrm{~km}$ further into the ocean (New and da Silva 2002). Nonetheless, the widespread occurrence of the local generation mechanism in other regions of the world's oceans has been recently put forward with the contribution of in situ and satellite data. In fact, several other studies have emerged since, which have also identified locally generated waves. Namely, the southern Bay 
Fig. 14.2 Subset of an Envisat-ASAR image (WS mode) showing a case of an ISW packet generated directly over the shelf. The image is dated 4 December 2009 and was acquired at $20 \mathrm{~h}$ $07 \mathrm{~m}$ UTC. It is centred approximately at $36.26^{\circ} \mathrm{E}$, $20.33^{\circ} \mathrm{S}$, with an area of about $77 \times 77 \mathrm{~km}^{2}$ to the east of Mozambique, which is outlined in Fig. 14.1 by the white square line

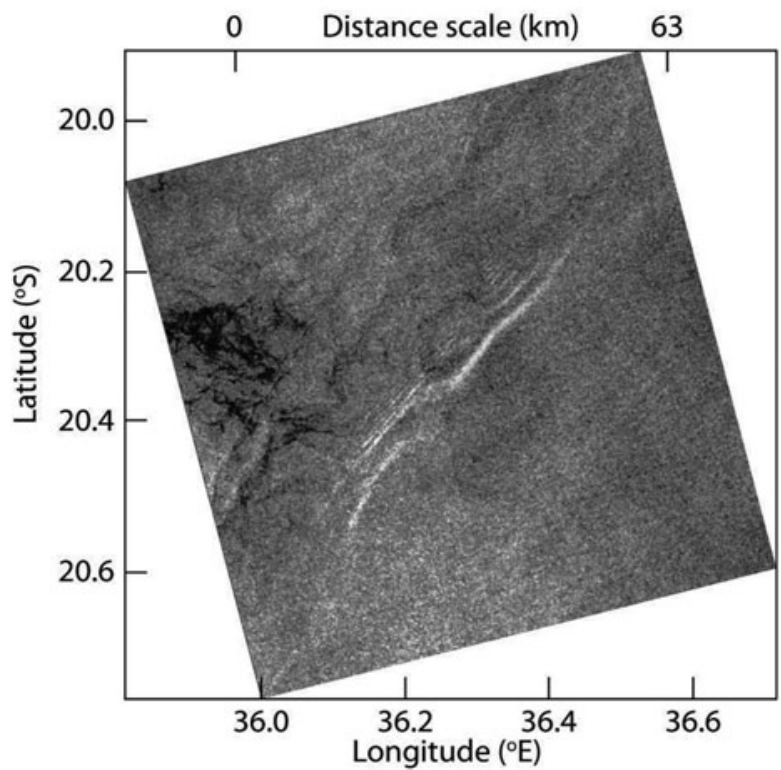

of Biscay (Azevedo et al. 2006), the Estremadura Promontory (da Silva et al. 2007), and more recently the MC (da Silva et al. 2009), have also been found as major hotspot regions for the local generation mechanism.

\subsubsection{SAR Evidence of ISWs}

Figure 14.2 presents a subset of an Envisat ASAR image (in Wide Swath mode, WS) from 4 December 2009 (centred at $36.26^{\circ} \mathrm{E}, 20.33^{\circ} \mathrm{S}$; see Fig. 14.1 for location), and corresponds to an area of approximately $77 \times 77 \mathrm{~km}^{2}$. Several ISWs can be identified as belonging to a packet resulting from direct generation over the shelf. Their sea surface signatures, which can be identified in the centre of the image, are consistent with mode 1 waves of depression.

At least 3 individual solitons are already formed in the northeast end of the packet, but their coherence is lost towards the other end. This together with the short wavelengths is an indication that these waves have been recently formed. Another example of ISWs propagating farther off the Sofala Bank is given in Fig. 14.3. This image shows a subset of an Envisat ASAR image, in Wide Swath (WS) mode, dated 7 April 2003 (centred at $36.6^{\circ} \mathrm{E}, 21.3^{\circ} \mathrm{S}$; see Fig. 14.1 for location), which corresponds to an area of approximately $76 \times 156 \mathrm{~km}^{2}$.

It is a typical example of the local generation mechanism with waves being generated locally and farther off-shelf than the ones shown in the previous example. Three well-developed waves can be clearly distinguished propagating towards the southeast with larger crestlengths compared with those in Fig. 14.2 (the first of which 
Fig. 14.3 Subset of an Envisat-ASAR image (WS mode) showing a typical case of locally generated ISWs. The image is dated 7 April 2003 and was acquired at $07 \mathrm{~h}$ $09 \mathrm{~m}$ UTC. It is centred approximately at $36.6^{\circ} \mathrm{E}$, $21.3^{\circ} \mathrm{S}$, with an area of about $76 \times 156 \mathrm{~km}^{2}$ to the east of Mozambique, which is outlined in Fig. 14.1 by the white rectangle

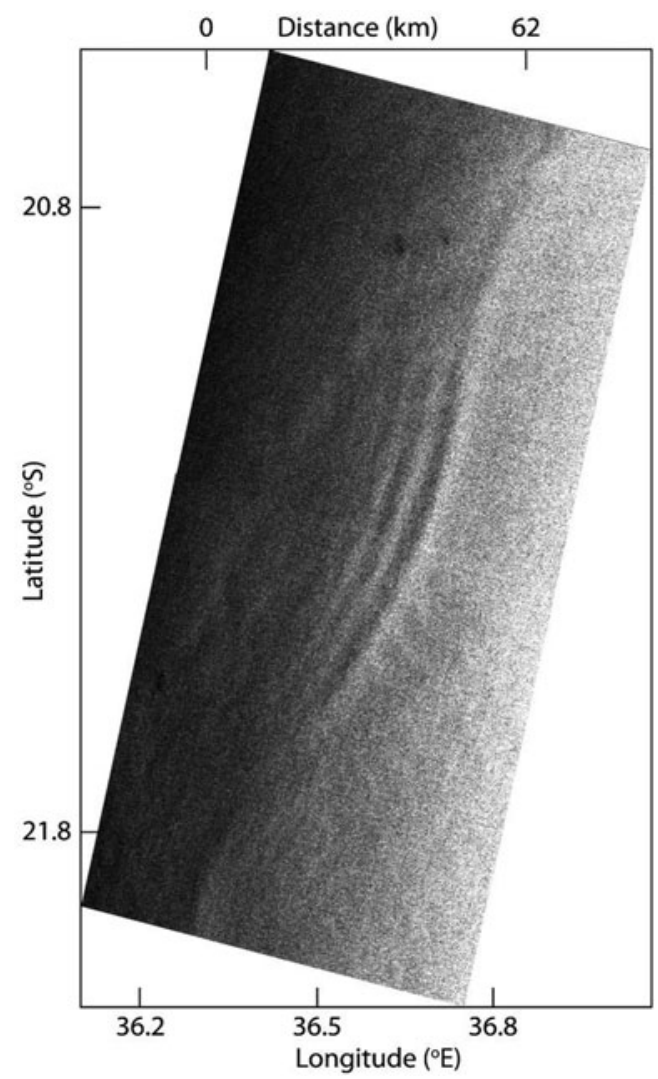

with more than $100 \mathrm{~km}$ ). It can also be seen that these individual waves are organized in a rank-ordered fashion, and that there are brighter bands preceding darker ones in the direction of propagation (a typical feature of mode 1 waves of depression).

Several other examples of ISW signatures have been found in similar images acquired over the MC. A composite map of these examples has been assembled (to be presented in the next Section) where it will be clearly seen that (similarly to the Bay of Biscay) there are two distinct concentrations of ISW signatures. These local maxima are consistent with simultaneous generation near the shelf-edge and farther offshore, owing to the local generation mechanism.

\subsubsection{Tidal Forcing}

We now examine the generation issue more closely in order to investigate the most likely locations for the generation of these IWs. To do so the methodology that is usually presented in the literature consists of two main steps. On the one hand, the 
Baines (1982) barotropic tidal forcing is often used to search and identify hotspot regions of ISWs within a given study area. It has proved to be a valuable indicator in several other independent studies, particularly to study the possibility of the local generation mechanism. For instance, Azevedo et al. (2006) and da Silva et al. (2007) have used this method to investigate the local generation mechanism in the southern Bay of Biscay (near Cape Finisterre), and in the southern slopes of the Estremadura Promontory (off the west Iberian shelf). In addition, there have been other authors that also used this technique over the last decade, as a valuable indicator of where large ITs may be generated (e.g. Colosi et al. 2001; Merrifield and Holloway 2002; Niwa and Hibiya 2004). On the other hand, ray-tracing techniques are used to see if the locations where ISWs first appear are consistent with the local generation mechanism (i.e. if the first ISW packets appear a few kilometers ahead of the expected impact of an IT beam with the pycnocline). Note that, ITs in a continuously stratified ocean can be described by beams or rays that follow characteristic pathways (along which their energy can propagate-see Eq. 14.1). In other words, this means that when the bottom slopes match the local value of $\tan (\theta)$ (called a critical region) the generation of ITs is more pronounced, particularly if the barotropic currents are strong. In such cases, the direction of the forcing barotropic flow is then coincident with the motion plane for free internal waves, resulting in resonant conditions and enhanced generation of the ITs and ISWs.

The barotropic forcing term (following Baines 1982) for ITs, resulting from the interaction of bottom topography and tidal flow, can be defined as

$$
F=-z N^{2}(z)\left[\int Q_{x} d t \frac{1}{h^{2}} \frac{\partial h}{\partial x}+\int Q_{y} d t \frac{1}{h^{2}} \frac{\partial h}{\partial y}\right]
$$

where $z$ is the vertical coordinate (positive upwards), $Q$ is the barotropic mass flux vector $Q=(u h, v h)$ with $u$ and $v$ being the zonal and meridional components of the barotropic velocity, and $h$ is the ocean depth. This means that $F$ can be analytically integrated provided that $Q$ is previously known, and for that purpose the components of the barotropic velocity vector were taken from the $1 / 8^{\circ}$ resolution OTIS model (Oregon state university Tidal Inversion Software, developed by Egbert and Erofeeva 2002). The model included the $\mathrm{M}_{2}$ and $\mathrm{S}_{2}$ tidal constituents (periods of 12.42 and $12.00 \mathrm{~h}$, respectively) of the barotropic tide since these are the most important in this study region (see da Silva et al. 2009). The bathymetry data is part of the one minute global bathymetry from Smith and Sandwell (1997), and $N$ (assumed to be spatially constant) is the same used in da Silva et al. (2009) for the October stratification (see their Fig. 2a).

Figure 14.4 shows the tidal ellipses for a complete semi-diurnal tidal cycle corresponding to the image in Fig. 14.2 (4 December 2009). These current ellipses, that are needed to calculate $Q$, were derived using least-squares fits to the data in each grid point. Note that the original outputs do not form perfectly closed ellipses due to the slowly varying nature of the tide.

It can be seen that the barotropic tidal currents achieve their biggest values over the continental shelf (in the Sofala Bank region), after crossing the $200 \mathrm{~m}$ depth contour. 
Fig. 14.4 Detailed bathymetry of the area outlined by the black rectangle in Fig. 14.1 together with ellipse tidal currents for the date of the image in Fig. 14.2

(4 December 2009). A reference ellipse is shown on the right-hand side (with both axes representing a speed of 1 $\mathrm{ms}^{-1}$ ). For clarity ellipses with axes below $0.05 \mathrm{~ms}^{-1}$ are not represented. Depth contours are also shown in meters (starting at 200,500, $1,000,1,500$ and $2,000 \mathrm{~m}$ ). A reference location for the Sofala Bank is labelled $S B$

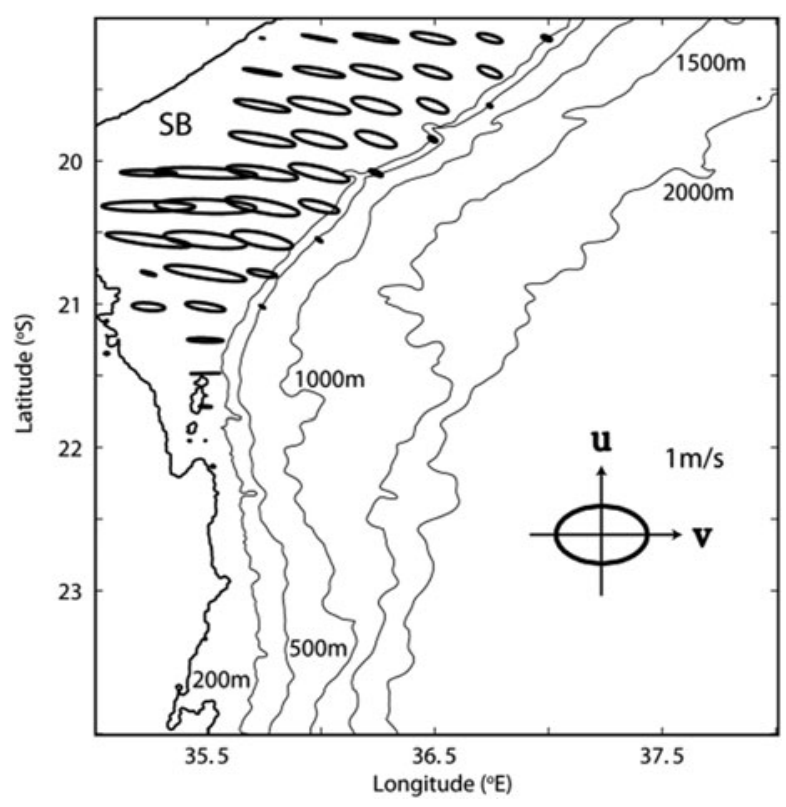

It can also be seen that these are approximately aligned with the bathymetry gradient. This indicates that there will be a strong tidal forcing owing to strong tidal currents passing directly over steep slopes. The magnitudes of these currents (see reference ellipse on the right) can reach relatively large values, some close to $1 \mathrm{~ms}^{-1}$ farther inside the inner-shelf. However, there is a rapid decrease in the tidal currents towards the open ocean areas that starts immediately after crossing the shelf-break (with an average depth of $50 \mathrm{~m}$ ). We note in passing, that these values over the Sofala Bank are in fact the biggest anywhere within $\mathrm{MC}$, and are among the biggest anywhere in the world.

Figure 14.5 shows the overall maximum of the depth-integrated body force within a complete semi-diurnal tidal cycle for the Sofala Bank area (with the tidal currents computed for 4 December 2009, and shown in Fig. 14.4). Together with this 2D body force, a composite map of ISWs observations is also shown for ease of interpretation, in terms of the hotspot regions associated with observations. The dataset used in the composite map contains a total of 6 images acquired from 2003 to 2006, during the southern spring and summer (a complete description may be found in da Silva et al. 2009; see their Table 1). Note that the present body force map shown in Fig. 14.5 was computed for a different day of the ISWs presented in this figure, but results would remain fairly the same for any other choice of dates. A closer inspection of the body force in Fig. 14.5 shows that there are localized regions of maximum forcing coincident with steep slopes and focused along a narrow line (with depths approximately between 100 and $500 \mathrm{~m}$ ) that is generally along the edge of the continental shelf. The tidal forcing is actually very weak everywhere else (in general), meaning that the body force values decay rapidly to zero in the shallower 


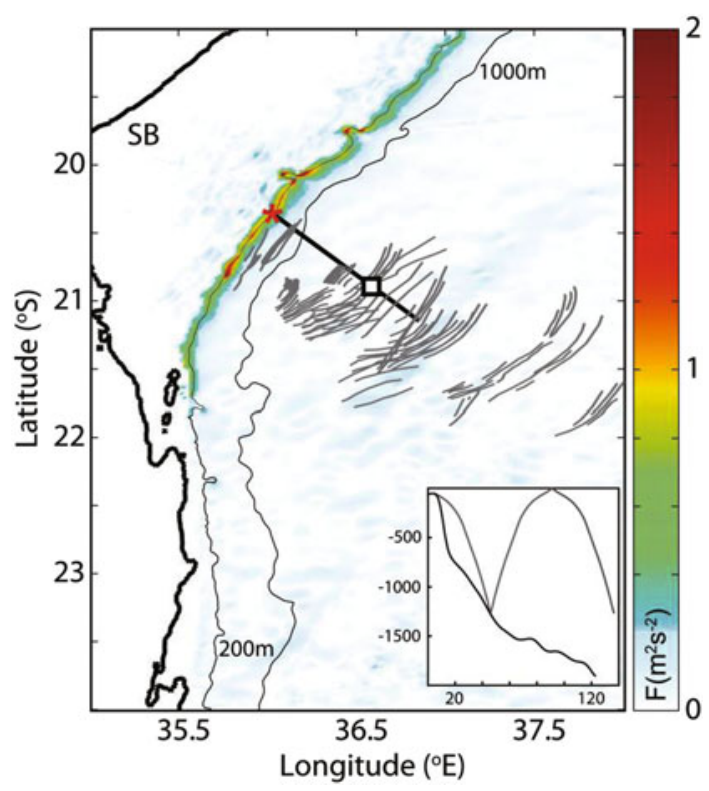

Fig. 14.5 Maxima of Baines (1982) depth-integrated body force $(F)$ over a complete tidal cycle, calculated using Eq. (14.2) for 4 December 2009 (same date as Figs. 14.2 and 14.4). The area shown corresponds to the black rectangle in Fig. 14.1. A reference location for the Sofala Bank is labelled $S B$. The coastline is marked by a black contour and the thin lines are the 200 and $1,000 \mathrm{~m}$ isobaths. A composite map of ISW observations (six in total, see text for details) propagating in MC is also shown in grey thick lines. The inset on the bottom-right corner is a vertical profile corresponding to the section in a black line, which goes from the region of maximum $\mathrm{F}$ towards the southeast, along the ISWs propagation path. The vertical and horizontal axes are depth in meters and distance in kilometres (measured from the northwest end). The vertical section shows a ray-tracing diagram for the $\mathrm{M}_{2}$ tidal constituent and assuming stratification typical for the summer in the MC. The red star in the map represents the critical bathymetry from where IT beams are generated, and the black square is the corresponding reemergence at the thermocline (see text for more details)

areas above $100 \mathrm{~m}$, and in the deep ocean basin that extends farther away into the MC.

The section shown by a black line in Fig. 14.5, which extends in an approximately perpendicular direction to the shelf-edge (from the northwest to the southeast), is representative of a vertical profile for IT ray-paths (see the inset shown in the lower right corner). The red star marks the position of critical bathymetry along that same profile for the $\mathrm{M}_{2}$ tidal constituent and using the October stratification used earlier (the same used to calculate $F$; see Fig. 2a in da Silva et al. 2009). The black square is the corresponding reemergence at the thermocline. It can be seen that there are internal tidal beams originating from critical topography coincident with elevated regions of $F$ that initially slope downward into the ocean interior. The IT beam then reflects upward from the seafloor between 1,100 and $1,300 \mathrm{~m}$, and reemerges later at the thermocline at about $90 \mathrm{~km}$ offshore. 
Considering the relative positions of the ISWs signatures and the geometry of the IT beam reflection, a region of low activity can be identified near the shelf-break that lies behind the re-emergence of IT energy. This region is followed by another area of ISW activity that closely coincides with the surfacing positions of the IT rays. Similarly to the case in the Bay of Biscay, this suggests that there is a region of elevated forcing near the shelf edge that is simultaneously generating ISWs directly above, and IT rays that are propagating to the deeper ocean, reflecting from the sea floor, and locally generating ISWs some $90 \mathrm{~km}$ farther offshore.

\subsection{Mode 2 ISWs}

\subsubsection{Introduction}

IWs propagation is naturally bounded, both above and below by the ocean's surface and bottom-thus confining them within a natural waveguide. However, the ocean's pycnocline can also be seen as another form of waveguide, since it confines the higher frequency oscillations into interfacial waves (e.g. the ISWs seen in SAR imagery). The vertical confinement imposed by these boundaries results in horizontally propagating waves, which nonetheless have a standing character in the vertical. In this case, a classical Sturm-Liuville problem arises if the linear equations of motions (under the Boussinesq and Traditional approximations) are solved with boundary conditions for zero vertical velocities at the surface and bottom of the ocean. Therefore, IW solutions with an infinite number of modes can either exist in nature on their own or in any number of combinations (see e.g. Gerkema and Zimmerman 2008 for a detailed description on IW dynamics). The first case, usually results in low mode propagation of IWs (like interfacial ITs or ISWs), while the second may result in an increasing superposition of modes, which makes the spatial appearance of the IW field to resemble a beam structure (like IT beams). In the particular case of SAR imagery, ISWs are generally described as interfacial mode 1 waves of depression (propagating along the pycnocline, and depressing it) that are usually ridding on the troughs of the IT (which is also an interfacial disturbance of the pycnocline). However, recent attention has been given to a different set of observations, where SAR surface signatures are not consistent with mode 1 ISWs, but rather suggest mode 2 solitary-like waves (for simplicity referred to in this chapter as mode 2 ISWs). In fact, despite that first-mode internal waves are most commonly observed in the ocean, higher-mode waveforms also occur under the proper conditions. A mode- 2 wave is best thought of in terms of a three-layer stratified ocean, when the middle-layer thickness is relatively thinner than the upper and lower layers. In this configuration, the wave travels as a bulge in the middle layer, displacing isopycnals upward into the upper layer and downward into the bottom layer (see e.g. Shroyer et al. 2010c).

Cases of satellite observations and in situ measurements of mode 2 oceanic ISWs are seldom, and they are hardly ever found in the literature. In fact, despite that they have long been predicted in theory, it was not until recently that they were seen to 


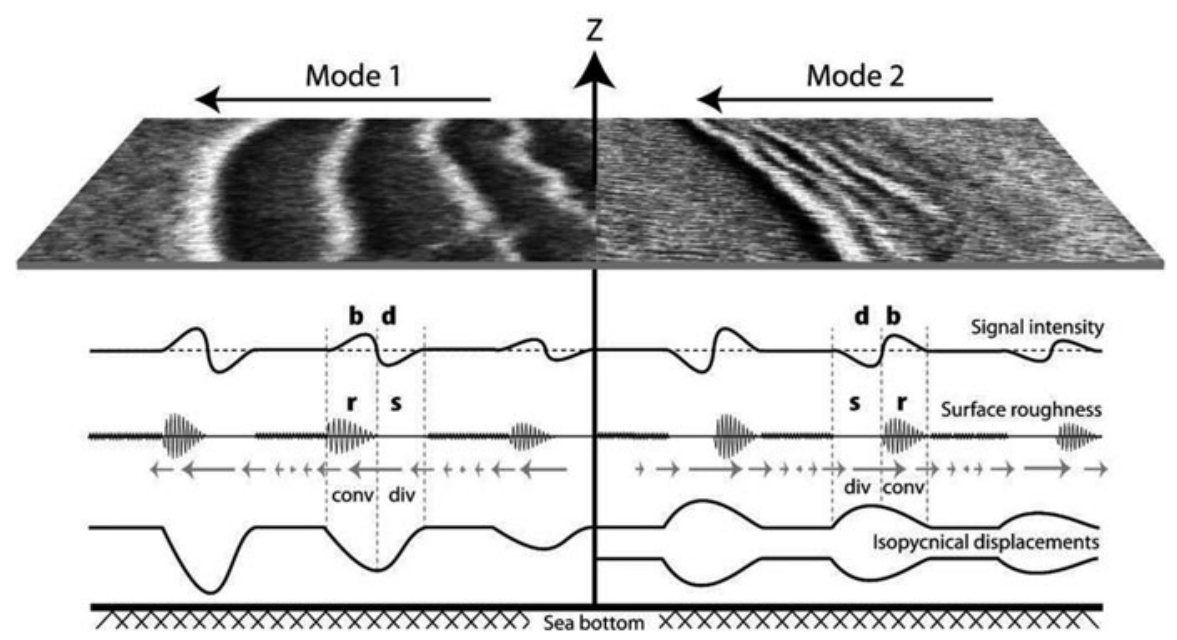

Fig. 14.6 Examples of SAR images with sea surface signatures of mode 1 and 2 ISWs are shown at the top (left and right, respectively). The ISWs are assumed to be moving from right to left. From top to bottom the horizontal profiles represent the following features: SAR intensity profile along the ISWs, with bright enhanced backscatter $(b)$ preceding dark reduced backscatter $(d)$ in the direction of propagation for mode 1 waves; surface roughness representation indicating how rough $(r)$ and smooth $(s)$ the surface is along an ISW wave packet; surface current variability induced by ISWs (note indication of convergence and divergence fields near the surface); isopycnical displacements produced by ISW propagation. Note how the SAR signatures, surface roughness, current fields and convergence and divergence patterns are all reversed between mode 1 (on the left) and mode 2 (on the right) ISWs

exist in nature using in situ and satellite image data (see e.g. Shroyer et al. 2010c; da Silva et al. 2011). However, SAR observations now suggest that mode 2 ISWs can be more frequent than previously acknowledged. In this Section it will be shown that mode 2 ISWs can also be observed in MC, and are generated by IT beams with semi-diurnal frequency.

Sea surface signatures of mode 1 and mode 2 ISWs can be unambiguously identified in SAR images provided the waves propagate in relatively deep water (when the lower layer is significantly deeper than mixed layer depth). If interfacial waves (in a two layer system) travelling along the pycnocline are waves of depression (which is often the case in deep waters), then mode 1 ISWs will be revealed in SAR images by bright bands preceding darker ones in their direction of travel (see Alpers 1985). However, mode 2 ISWs will have exactly the opposite contrast in the SAR, since their radar signature consists of dark bands preceding bright bands in their direction of propagation (see Fig. 14.6).

This is because surface velocity fields induced by travelling ISWs of different modes can create different convergence and divergence patterns, which then modulate the surface roughness and thus the intensity of the radar backscatter signal. In particular, a mode 2 ISW travelling along the thermocline will generate a divergence pattern at the surface, followed by a convergence pattern in the propagation direction 
(see Fig. 14.6). It is this dynamical feature (reversed with respect to mode 1 ISWs) that produces the characteristic dark bands ahead of the bright bands in their direction of travel.

Research studies on mode 2 ISWs generated by IW rays hitting a pycnocline have been recently presented using numerical models and laboratory experiments (Grisouard et al. 2011 and Mercier et al. 2012, respectively). These studies were focused on the local generation mechanism (see Sect. 14.2), and have also addressed the generation of higher mode waves by IW rays. Grisouard et al. (2011) used a (nonlinear and non-hydrostatic) numerical model and concluded that higher mode ISWs (particularly mode 2) may also be generated by an IW beam hitting a pycnocline at an angle. In their studies, high mode waves are favoured by a strongly stratified pycnocline or, equivalently, by short-wavelength IT beams. Laboratory measurements of ISWs generated by an internal wave beam were presented by Mercier et al. (2012), and are in agreement with the results of Grisouard et al. (2011). Following these numerical and laboratory studies, we will now show satellite observations of mode 2 ISWs, which are consistent with local generation by an IW beam impinging on the ocean pycnocline from below.

\subsubsection{SAR Observations of Mode 2 ISWs}

Figure 14.7 shows a typical example of a SAR image where two wave trains can be seen to propagate towards the shore (approximately to the west-northwest, and in a near perpendicular direction to the local isobaths) in the southern end of MC (near parallel $24^{\circ} \mathrm{S}$ ). The left panel shows an ERS-2 SAR image dated 24 September 2001 (acquired at 7:39 UTC), which is centred approximately at $23.75^{\circ} \mathrm{S}$ and $35.75^{\circ} \mathrm{E}$. Note that land and coast lines are also marked in gray areas outlined by a black contour, respectively, and that bathymetry levels for 100, 200, 500 and 1,000 m are also shown. The black filled circle on the image indicates the predicted position where an IT beam would impinge on the thermocline from below (assumed at an average depth of $50 \mathrm{~m}$ ), and the dashed line indicates its trajectory coming from deeper bathymetry to the east (passing through the centre and taken perpendicular to the wave crests). The right hand side of Fig. 14.7 shows a vertical profile, which is aligned and partially coincident with the black dashed line on the left, together with a simulated IT beam of semi-diurnal frequency based on local stratification. The arrow indicates the direction of energy propagation, and the inset shows the geographic location of the observation (the star in the inset denotes the geographic location of the image centre).

The SAR image shown in Fig. 14.7 reveals that the ISWs in the deeper wave packet are characterized by the usual rank-ordered bright and dark bands of radar intensity, which decrease in amplitude from the front to the rear. However, while these signatures look like many other typical SAR signatures of ISWs, it can be seen that in this case the contrast pattern is reversed in relation to the general pattern (of mode 1 ISWs). Here, dark bands precede bright bands in the propagation direction, 


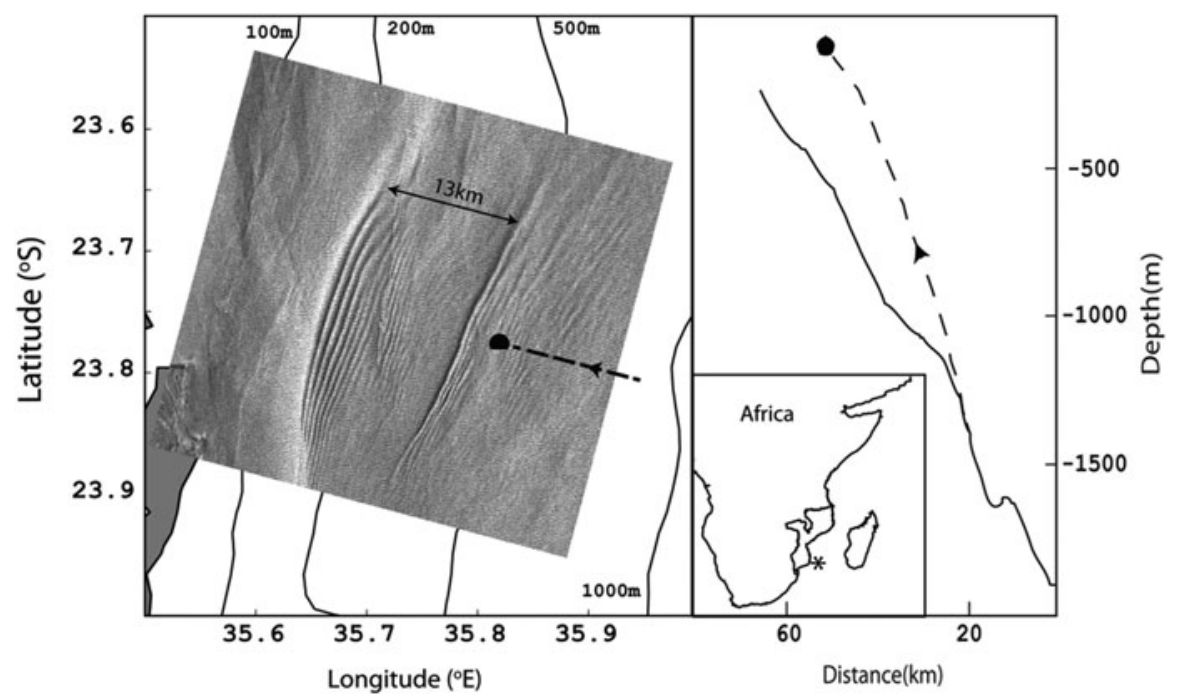

Fig. 14.7 ERS2-SAR image dated 24 September 2001 and acquired at 7:39 UTC, showing two packets of ISWs consistent with a mode 2 vertical structure (separated by $\sim 13 \mathrm{~km}$ ). Isobaths for depths of 100, 200, 500, and 1,000 $\mathrm{m}$ are also shown. On the right hand side a vertical profile corresponding to the dashed section on the left (perpendicular to the ISW crests) is shown with a simulated ray trajectory (dashed line) coming from critical bathymetry and based on local stratification (the arrows indicate the direction of energy propagation). The black circle on both panels indicates the predicted position where an IT beam impinges on the thermocline from below. The inset shows the geographic location of the observation in the Mozambique Channel

indicating that these radar signatures are consistent with mode 2 ISWs (see schematics shown in Fig. 14.6 for mode 2 ISWs). Another important characteristic of this image is that it shows the ISWs to appear close to (but in front of) the surfacing position of the predicted IT rays of semi-diurnal frequency (with a $\mathrm{M}_{2}$ tidal constituent), generated at the critical slopes farther east. This strongly suggests that these mode 2 ISWs are generated locally after the impact of an IT beam in the pycnocline from below. We note that, this is in agreement with the numerical and laboratory studies done by Grisouard et al. (2011) and Mercier et al. (2012), respectively, since they too predicted the possibility of ISWs with higher mode structures being "locally generated".

\subsubsection{Comparison of Average Propagation Speeds with Theory}

To reinforce the hypothesis that the observed ISWs in Fig. 14.7 are of mode 2, we will also estimate an average phase speed from the SAR image, and compare it with a theoretical model. To do so the Taylor-Goldstein (TG) model is used, which is solved numerically to investigate the propagation speeds of the lowest IT modes (see 
e.g. Kundu and Cohen 2004). For the MC case, we have assumed a semi-diurnal frequency for the IT with a $\mathrm{M}_{2}$ tidal constituent (with $\sigma=1.4 \times 10^{-4} \mathrm{rad} \mathrm{s}^{-1}$ ), and a mean density profile typical for the southern winter stratification (namely October, see Fig. 2a of da Silva et al. 2009). Based on Fig. 14.7, we also considered an average ocean depth of $300 \mathrm{~m}$ to the west of the ISWs along their apparent propagation path (region between the two consecutive packets that are observed in the SAR). Additionally, we assumed that the two packets in Fig. 14.7 were generated at the same phase of the tide and at the same position - that is near the impact point of the IT beams with the pycnocline. Under those assumptions, and considering that the two ISW packets in the SAR are separated along their apparent propagation path by an average distance of $13 \mathrm{~km}$ (see black arrow on top of left panel in Fig. 14.7), the estimated phase speed of the mode 2 ISWs in the SAR is $0.3 \mathrm{~ms}^{-1}$. On the other hand, the TG model assuming an average depth of $300 \mathrm{~m}$ predicts linear phase speeds of 0.4 and $1.0 \mathrm{~ms}^{-1}$ for mode 2 and mode 1 linear IWs of tidal frequency, respectively. This further suggests that the waves in Fig. 14.7 are indeed mode 2 waves, since both signatures (discussed in Sect. 14.3.2) and phase speeds are consistent with a mode 2 vertical structure.

\subsection{Eddy-Like Structures and IW Refraction}

Da Silva et al. (2009) reported that, on some occasions, ISWs in MC (off the Sofala Bank; see Fig. 14.1 for location) were observed farther south than the average pattern. In their study, the seasonal variability of currents during the southern winter was the plausible explanation for this ISWs propagation anomaly. To justify this seasonal variability they referred to the work done by Maltrud et al. (1998), who believed that the Mozambique Current (which flows southward along the western slopes of the basin) was much stronger during the austral winter. Based on the knowledge of the Mozambique Current available at that time, da Silva et al. (2009) then proposed that the increased southward flow in the southern winter months could explain why some ISWs were refracted (or advected) towards more southerly pathways at that time of year. However, more recent research indicates that the MC currents are in fact highly variable, which is mainly due to the presence of eddy-like features that originate in the Indian Ocean and travel southwards throughout MC (Ridderinkhof et al. 2010; Ullgren et al. 2010). In this Section, we will show an example of ISWs propagating through eddy-like structures (which are observed in altimetry data) and undergoing dramatic refraction patterns.

Figure 14.8 shows a map of ISWs based on our interpretation of an Envisat ASAR image (WS mode), acquired on 4 December 2009 at 20:07 UTC, that is centred approximately at $21.0^{\circ} \mathrm{S}$ and $36.3^{\circ} \mathrm{E}$. For clarity, two types of wave packets (discussed earlier in Sect. 14.2) were marked with 'SG' for shelf-generation and 'LG' for local generation), until they reach $21.5^{\circ} \mathrm{S}$.

This is because further south of $21.5^{\circ} \mathrm{S}$ along their trajectory, the interpretation of the sea surface signatures starts to become ambiguous, mainly due to dissipation, 


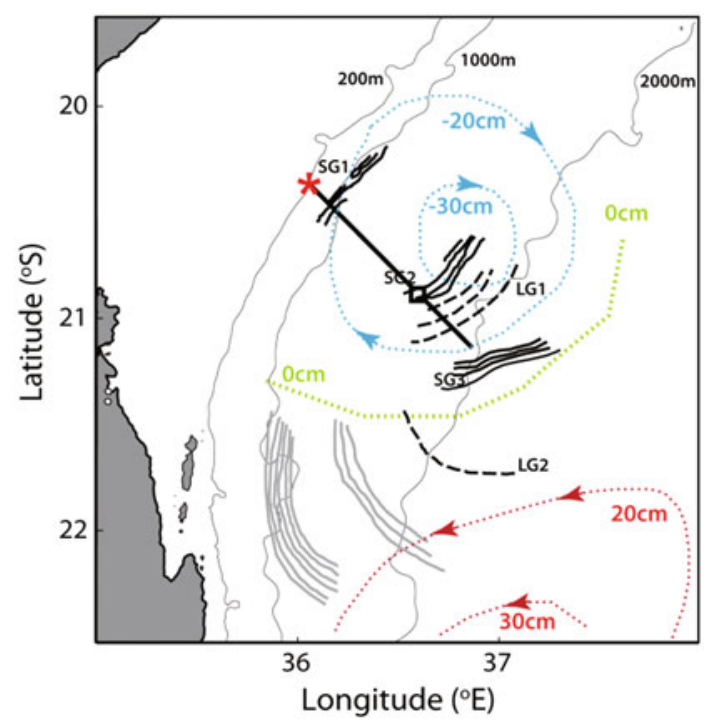

Fig. 14.8 Location map for ISWs observed to propagate in an Envisat-ASAR image (WS mode) over the Mozambique Channel, dated 4 December 2009 and acquired at $20 \mathrm{~h} 07 \mathrm{~m}$ UTC. Land is shown in grey areas and isobaths for 200, 1,000, and 2,000 $\mathrm{m}$ are marked in thin black lines. ISWs interpreted to be generated directly over the shelf $(S G)$ are in solid black lines, while locally generates waves $(L G)$ are in dashed black lines. Each group is numbered chronologically from their generation to later stages of development. ISWs that could not be discriminated (for their generation mechanism) are marked in grey (see text for details). The red star, the black square, and the black section are the same as in Fig. 14.5, and are shown here for a reference location of critical bathymetry and the re-emergence of IT rays at the thermocline. The blue and red dashed lines mark the locations of eddy-like features detected in altimetry data, and whose rotation is indicated by arrows. The green line represents a reference level of neutral sea surface height

interactions with currents and winds, and interaction among different ISW packets. We note that, this interpretation is further reinforced if the average propagation speeds of the several packets are taken into account. Indeed, according to da Silva et al. (2009), the average phase speeds of these waves were found to be around 1.5 $\mathrm{ms}^{-1}$, and the same values can also be found for the sequences SG1, SG2, and SG3, and LG1 and LG2 - based on distances measured in the SAR. The map in Fig. 14.8 also displays Sea Surface Height ( $\mathrm{SSH}$ ) anomalies taken from altimetry data ${ }^{1}$, where different colours and dashed quasi-circular lines are used to indicate the presence of eddy-like features observed at approximately the same time as the SAR image (4 December 2009 at 00:00 UTC, the closest product available in time). The blue and red curves refer to negative and positive SSH anomalies, respectively, and a green line has been drawn for reference indicating the boundary between them (an apparent reference level).

\footnotetext{
${ }^{1}$ Namely, from Topex-Poseidon data products. The altimeter products were produced by Ssalto/Duacs and distributed by Aviso, with support from Cnes (http://www.aviso.oceanobs. com/duacs/).
} 
There are tangential surface currents associated to these SSH anomalies, whose rotation directions are indicated by arrows in Fig. 14.8. These currents can be rather large in the MC (as large as $0.5 \mathrm{~ms}^{-1}$ according to Swart et al. 2010 and thus of the order of the ISWs propagation speeds) and their influence can extend in diameter for some $200 \mathrm{~km}$. In terms of vertical sections the SSH anomalies are associated with isopycnical deformations, which are in general in the opposite way to the surface displacements. From Fig. 14.8, it is clear that the eddy-like features associated to the SSH anomalies interfere with the propagation of the ISWs, apparently causing an overall refraction pattern (to be discussed in the next paragraphs).

In the southern hemisphere eddies with an anti-clockwise rotation are warm eddies, whose SSH anomalies are positive at the surface but are characterized by bowl-like (or bulge) downward displacements of their isopycnicals at depth (isopycnicals can be displaced some $100 \mathrm{~m}$ downwards or more, at the core of a warm eddy near the pycnocline). On the other hand, cold eddies spin in the clockwise direction, which are characterized by negative SSH anomalies, and have their isopycnicals displaced upwards near the core.

This means that the eddy-like features identified in Fig. 14.8 are those of a cold eddy just off the Sofala Bank (in blue), and a warm eddy somewhat farther south and farther offshore (in red). It can be seen that the ISW crests showed in Fig. 14.8 are clearly interacting with the eddy structures that were measured in the SSH data. First, the cold eddy closer to the shelf and afterwards the warm eddy farther offshore (and southwards of the cold eddy) are located directly along the ISWs path. Note that the sequence of ISW crests shown in Fig. 14.8 also exhibits what appears to be a clockwise rotation pattern.

In fact, the packets labelled SG1, SG2, LG1, SG3 and LG2 (forming a chronological sequence) progressively propagate more to the south and less to the east, until they reverse the component of east-west propagation velocity and return back on to the shore, undergoing a near 135 clockwise rotation. In this interpretation, we considered that the ISWs sequence mentioned above is progressively older in time, with respect to their generation sites and propagation paths. We believe that the pattern of ISWs rotating clockwise in their direction of propagation is essentially caused by interaction with the near-surface currents produced by eddies. However, refraction may also be caused (at least to some extent) by different stratifications and mixed layer depths resulting from the relative positions of eddies along the ISWs propagation pathways. The later effect has been explained successfully by Sherwin et al. (2002) off the northern Portuguese shelf (in the west Iberian Coast), where refraction of ISWs occurs basically due to an offshore downward tilt of the isopycnicals. In the Iberian case, similarly to the MC, ISWs were first found to propagate in an off-shelf direction and then refract back onto the coast some $50 \mathrm{~km}$ north of their generation site (roughly the same distance that ISWs need in MC to refract back to shore). 
Fig. 14.9 Envisat-MERIS image dated 16 September 2004 and acquired at $07 \mathrm{~h}$ $15 \mathrm{~m}$ UTC. The image covers an area of about $580 \times 660 \mathrm{~km}^{2}$ and is centred near $20.4^{\circ} \mathrm{S}$ and $38.0^{\circ} \mathrm{E}$. The black compass overlaid on the top-left corner indicates north, and the black circle has been drawn to have approximately $70 \mathrm{~km}$ in diameter (for a scale reference). Two waves can be seen in the southwest part of the Mozambique Channel, one large-scale $\mathrm{AGW}(L)$ going southwest and a smaller AGW $(S)$ going southeast

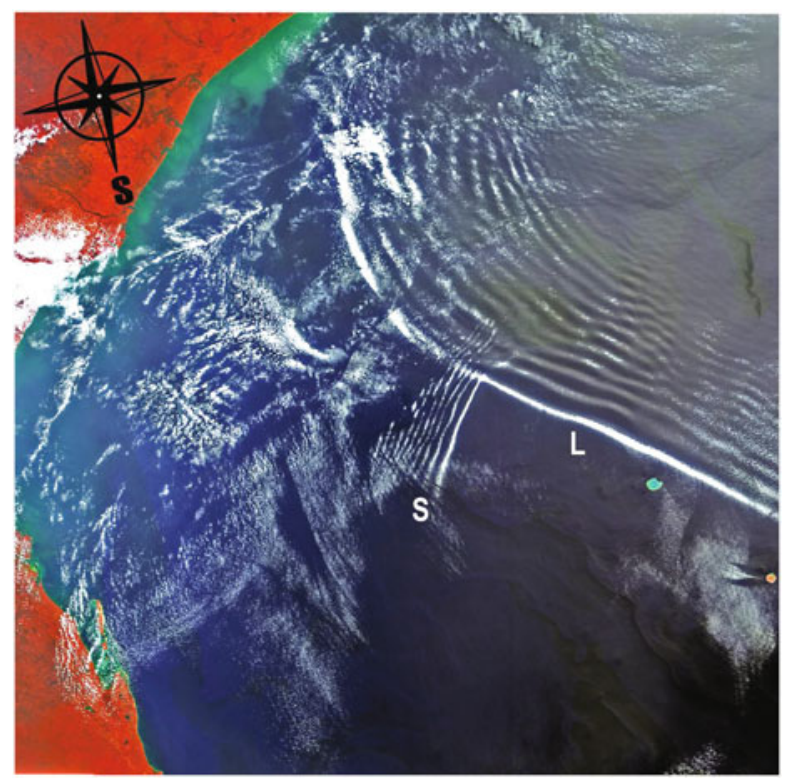

\subsection{AGWs in the MC and Oceanic ISW Look-Alikes}

In the previous Sections we have clearly shown that $\mathrm{MC}$ is a hotspot for oceanic IWs, which adds to the idea that these features represent ubiquitous phenomena in the world's oceans. However, MC is also a region where atmospheric IWs are frequently observed, being amongst the largest (in terms of spatial scales and crestlengths) observed anywhere in the world (see da Silva and Magalhaes 2009).

A particular case of large-scale AGWs propagating in $\mathrm{MC}$ can be found in Fig. 14.9, where we present a RGB composite from an Envisat-MERIS image dated 16 September 2004, and acquired at 07:15 UTC. The image covers an area of about $580 \times 660 \mathrm{~km}^{2}$ in the southwest part of $\mathrm{MC}$, and it is centred near $20.4^{\circ} \mathrm{S}$ and $38.0^{\circ} \mathrm{E}$. A large-scale AGW can be seen in the centre of the image (labeled L), and travelling southwest towards the south end of MC. The crestlength of the leading wave, in this case, extends for more than $500 \mathrm{~km}$ and its crest-to-crest spatial scale is approximately $10 \mathrm{~km}$ on average. It is interesting to note that several (but not all) of these individual waves are made visible by characteristic cloud bands, which have considerable lateral extensions and uniform cross-sections.

Satellite imagery (mainly SAR, visible and near infrared) exhibiting these largescale AGWs are a regular occurrence in MC, particularly between July and October when they are more frequently observed. Satellite data (such as MODIS, MERIS and Envisat-ASAR in WS mode) have been used to characterize the horizontal structure of these AGWs, which have mean dispersive wavelengths between 3.5 and $8.5 \mathrm{~km}$, mean crestlengths of $443 \mathrm{~km}$, and propagation speeds that can exceed $10 \mathrm{~ms}^{-1}$. Two preferential pathways were found to dominate the AGWs, which propagate 
mainly to northeast (from the south end of the MC) and to southwest (coming from Madagascar). It was also found that high pressure systems born in the Polar Regions (known as Moving Polar Highs, MPHs), which are associated with air subsidence in $\mathrm{MC}$, can play a major influence on the propagation of these waves. This is because MPHs change the atmosphere's stability, and influences its vertical structure to form suitable waveguides, necessary for AGWs to propagate, and can even trigger their own generation (see da Silva and Magalhaes 2009 for a detailed study).

The sea surface signatures of the AGWs in MC can usually be distinguished from their oceanic counter parts (discussed in Sect. 14.2 to 14.4) due to their large dimensions (wavelength and crestlength). However, in many cases, other smallerscale AGWs can also be found to propagate across the $\mathrm{MC}$, including those areas where oceanic ISWs are frequently present (e.g. see composite map in Fig. 14.5). A good example can be seen in Fig. 14.9, where a small-scale AGW (labeled S, and much smaller than the largest packet labeled L) is seen to travel to the southeast, in an almost perpendicular direction to the larger-scale AGW (labeled L) that is travelling southwest. In fact, this observation is very similar to the oceanic ISWs presented in Sect. 14.2, since it has the same characteristics (namely, spatial scales, crests orientation, propagation direction and geographic location).

Care should be taken when interpreting sea surface manifestations of IWs in SAR (as mentioned in the Introduction Section). On the one hand, SAR images cannot detect the presence of cloud structures, which would clearly indicate the atmospheric nature of AGWs. On the other hand, clouds may not form at all in the presence of large amplitude AGWs, since the ascending branches of the waves may not meet the necessary moisture for condensation to occur. In fact, Fig. 14.9 shows that some of the solitary waves in the trailing edge of the large packet (labeled L) are only partially recognizable as clouds - the remaining segments are merely seen as sea surface patterns of banded roughness on a smoother background. In such cases, alternative methodologies should be taken under consideration to discriminate between oceanic and atmospheric IWs. A detailed discussion of these issues can be found in the work presented by Alpers and Huang (2011), where lists of discriminating criteria were presented based on soliton and SAR theory, and further complemented by additional information on the ocean and atmosphere.

\subsection{Summary}

This chapter describes remote sensing data from SARs and image spectrometers to clearly show that MC is a hotspot for observing ISWs in the ocean and in the atmosphere. Oceanic ISWs were found to be generated directly off the shelf by the steepening of an interfacial tidal wave, and through a different generation mechanism by which the impact of a tidal beam from below the thermocline generates ISWs (known as local generation of ISWs). Both mechanisms are associated with an elevated region of body forcing near the Sofala Bank, which results from strong 
barotropic tidal currents interacting with critical slopes. SAR imagery has also revealed that the MC is a preferential region for observing other IW phenomena such as mode 2 ISWs and strong refraction patterns. The data suggests that the mode 2 ISWs have also been generated by tidal beams, similarly to some of the mode 1 waves observed in the SAR. This confirms some conclusions drawn from other independent studies using modeling and laboratory experiments (Grisouard et al. 2011 and Mercier et al. 2012, respectively) about the origin of mode 2 solitary-like waves by tidal beams. The refraction patterns in SAR revealed that it is likely that ISWs in MC can frequently interact with oceanic features such as eddy-like structures, which propagate year-round through the MC and affect the local vertical structure of the ocean. Large-scale AGWs are also a ubiquitous feature in MC, especially from July to October, and care should be taken to avoid miss-interpretations in SAR with oceanic ISWs.

\section{References}

Akylas TR, Grimshaw RHJ, Clark SR, Tabaei A (2007) Reflecting tidal wave beams and local generation of solitary waves in the ocean thermocline. J Fluid Mech 593:297-313. doi:10.1017/S0022112007008786

Alpers W (1985) Theory of radar imaging of internal waves. Nature 314:245-247. doi: $10.1038 / 413245 \mathrm{a} 0$

Alpers W, Huang W (2011) On the discrimination of radar signatures of atmospheric gravity waves and oceanic internal waves on synthetic aperture radar images of the sea surface. IEEE Trans Geosci Remote Sens 49(3):1114-1126

Alpers W, Stilke G (1996) Observations of a nonlinear wave disturbance in marine atmosphere by synthetic aperture radar aboard the ERS 1 satellite. J Geophys Res 101:6512-6525

Azevedo A, da Silva JCB, New AL (2006) On the generation and propagation of internal waves in the southern Bay of Biscay. Deep-Sea Res Part I 53:927941. doi:10.1016/j.dsr.2006.01.013

Baines PG (1982) On internal tides generation models. Deep-Sea Res Part I 29:307-338. doi:10.1016/0198-0149(82)90098-X

Bedard AJ, Canavero F, Einaudi F (1986) Atmospheric gravity waves and aircraft turbulence encounters. J Atmos Sci 43(23):2838-2844

Colosi JA, Beardsley RC, Lynch JF, Gawarkiewicz G, Chiu CS, Scotti A (2001) Observations of nonlinear internal waves on the outer New England continental shelf during the summer Shelfbreak Primer study. J Geophys Res 106(C5):9587-9601. doi:10.1029/2000JC900124

Christie DR, Muirhead KJ (1983) Solitary waves: a hazard to aircraft operating at low altitudes. Aust Meteorol Mag 31:97-109

Crook AN (1986) The effect of ambient stratification and moisture on the motion of atmospheric undular bores. J Atmos Sci 43(2):171-181

da Silva JCB, Helfrich KR (2008) Synthetic aperture radar observations of resonantly generated internal solitary waves at Race Point Channel (Cape Cod). J Geophys Res 113:C11016. doi:10.1029/2008JC005004

da Silva JCB, Magalhaes JM (2009) Satellites observations of large atmospheric gravity waves in the Mozambique Channel. Int J Remote Sens 30(5):1161-1182

da Silva JCB, Ermakov SA, Robinson IS, Jeans DRG, Kijashko SV (1998) Role of surface films in ERS SAR signatures of internal waves on the shelf. 1. Short-period of internal waves. J Geophys Res 103(C4):8009-8031. doi:10.1029/97JC02725 
da Silva JCB, New AL, Srokosz M, Smyth T (2002) On the observability of internal tidal waves in remotely-sensed ocean color data. Geophys Res Lett 29(12):1569-1572. doi:10.1029/2001GL013888

da Silva JCB, New AL, Azevedo A (2007) On the role of SAR for observing "local generation" of internal solitary waves off the Iberian Peninsula. Can J Remote Sens 33:388-403. doi:10.5589/m07-041

da Silva JCB, New AL, Magalhaes JM (2009) Internal solitary waves in the Mozambique Channel: observations and interpretation. J Geophys Res 114:C05001. doi:10.1029/2008JC005125

da Silva JCB, New AL, Magalhaes JM (2011) On the structure and propagation of internal solitary waves generated at the Mascarene Plateau in the Indian Ocean. Deep-Sea Res Part I 58:229-240. doi:10.1016/j.dsr.2010.12.003

Egbert GD, Erofeeva SY (2002) Efficient inverse modeling of barotropic ocean tides. J. Atmos. Oceanic Technol 19:183-204. doi:10.1175/1520-0426(2002)019<0183:EIMOBO > 2.0.CO;2

Gerkema T (2001) Internal and interfacial tides: beam scattering and local generation of solitary waves. J Mar Res 59:227-255. doi:10.1357/002224001762882646

Gerkema T, Zimmerman JTF (2008) An introduction to internal waves. Lecture notes, Royal NIOZ, pp. 207

Grisouard N, Staquet C, Gerkema T (2011) Generation of internal solitary waves in a pycnocline by an internal wave beam: a numerical study. J Fluid Mech 676:491-513. doi:10.1017/jfm.2011.61

van Haren H, Groenewegen R, Laan M, Koster B (2005) High sampling rate thermistor string observations at the slope of Great Meteor Seamount. Ocean Sci 1:17-28. doi:10.5194/os-1-172005

Jackson CR (2007) Internal wave detection using the moderate resolution imaging spectroradiometer (MODIS). J Geophys Res 112:C11012. doi:10.1029/2007JC004220

Jackson CR, da Silva JCB, Jeans G (2012) The generation of nonlinear internal waves. Oceanography 25(2):108-123. doi:http://dx.doi.org/10.5670/oceanog.2012.46

Kundu PK, Cohen IM (2004) Fluid Mechanics. Third Edition. Academic Press. pp. 759

Lamb KG, Farmer D (2011) Instabilities in an internal solitary-like wave on the Oregon Shelf. J Phys Oceanogr 41:67-87. doi:10.1175/2010JPO4308.1

Magalhaes JM, Araújo IB, da Silva JCB, Grimshaw RHJ, Davis K, Pineda J (2011) Atmospheric gravity waves in the Red Sea: a new hotspot. Nonlinear Proc Geoph 18:71-79. doi:10.5194/npg18-71-2011

Maltrud ME, Smith RD, Semtner AJ, Malone RC (1998) Global eddy-resolving ocean simulations driven by 1985-1995 atmospheric winds. J Geophys Res 103:30825-30853. doi:10.1029/1998JC900013

Mercier MJ, Mathur M, Gostiaux L, Gerkema T, Magalhaes JM, da Silva JCB, Dauxois T (2012) Soliton generation by internal tidal beams impinging on a pycnocline: laboratory experiments. J Fluid Mech 704:37-60

Merrifield MA, Holloway PE (2002) Model estimates of M2 internal tide energetics at the Hawaiian Ridge. J Geophys Res 107(C8):3179. doi:10.1029/2001JC00996

Moum JN, Farmer DM, Smyth WD, Armi L, Vagle S (2003) Structure and generation of turbulence at interfaces strained by internal solitary waves propagating shoreward over the continental shelf. J Phys Oceanogr 33:2093-2112. doi:10.1175/1520-0485(2003)033<2093:SAGOTA > 2.0.CO;2

Nash JD, Moum JN (2005) River plumes as a source of large-amplitude internal waves in the coastal ocean. Nature 437:400-403. doi:10.1038/nature03936

New AL, da Silva JCB (2002) Remote-sensing evidence for the local generation of internal soliton packets in the central Bay of Biscay. Deep-Sea Res Part I 49:915-934. doi:10.1016/S09670637(01)00082-6

New AL, Pingree RD (1992) Local generation of internal soliton packets in the central Bay of Biscay. Deep-Sea Res Part A 39:1521-1534. doi:10.1016/0198-0149(92)90045-U

Niwa Y, Hibiya T (2004) Three-dimensional numerical simulation of M2 internal tides in the East China Sea. J Geophys Res 109(C4) C04027. doi:10.1029/2003JC001923 
Pingree RD, New AL (1989) Downward propagation of internal tidal energy into the Bay of Biscay. Deep-Sea Res Part A 36:735-758 doi:10.1016/0198-0149(89)90148-9

Pingree RD, New AL (1991) Abyssal penetration and bottom reflection of internal tidal energy in the Bay of Biscay. J Phys Oceanogr 21:28-39. doi:10.1175/15200485(1991)021<0028:APABRO > 2.0.CO;2

Pingree RD, Mardell GT, New AL (1986) Propagation of internal tides from the upper slopes of the Bay of Biscay. Nature 312:154-158. doi:10.1038/321154a

Pinkel R (2000) Internal solitary waves in the warm pool of the western equatorial pacific. J Phys Oceanogr 30:2906-2926. doi:10.1175/1520-0485(2001)031 < 2906:ISWITW > 2.0.CO;2

Reeder MJ, Christie DR, Smith RK, Grimshaw RHJ (1995) Interacting morning glories over northern Australia. Bull Amer Meteor Soc 76:1165-1171

Ridderinkhof H, van der Werf PM, Ullgren JE, van Aken HM, van Leeuwen PJ, de Ruijter WPM (2010) Seasonal and interannual variability in the Mozambique Channel from moored current observations. J Geophys Res 115:C06010. doi:10.1029/2009JC005619

Sandstrom H, Elliott JA (1984) Internal tide and solitons on the Scotian Shelf: a nutrient pump at work. J Geophys Res 89(C4):6415-6426. doi:10.1029/JC089iC04p06415

Sherwin TJ, Vlasenko VI, Stashchuk N, Jeans DRG, Jones B (2002) Along-slope generation as an explanation for some unusually large internal tides. Deep-Sea Res Part I 49:1787-1799. doi:10.1016/S0967-0637(02)00096-1

Shroyer EL, Moum JN, Nash JD (2010a) Vertical heat flux and lateral mass transport in nonlinear internal waves.Geophys Res Lett 37:L08601. doi:10.1029/2010GL042715

Shroyer EL, Moum JN, Nash JD (2010b) Energy transformations and dissipation of nonlinear internal waves over New Jersey's continental shelf. Nonlinear Proc Geoph 17:345-360. doi:10.5194/npg-17-345-2010

Shroyer EL, Moum JN, Nash JD (2010c) Mode 2 waves on the continental shelf: ephemeral components of the nonlinear internal wavefield. J Geophys Res 115:C07001. http://dx.doi.org/10.1029/2009JC005605

Smith WHF, Sandwell DT (1997) Global sea floor topography from satellite altimetry and ship depth soundings. Science 277(5334):1956-1962. doi:10.1126/science 277.5334.1956

Swart NC, Lutjeharms JRE, Ridderinkhof H, de Ruijter WPM (2010) Observed characteristics of Mozambique Channel eddies. J Geophys Res 115:C09006. doi:10.1029/2009JC005875

Ullgren J, van Aken H, Ridderinkhof H (2010) Unique measurements of ocean currents east of Africa. NIOZ Annual Report 2010, 21-22

Vlasenko V, Alpers W (2005) Generation of secondary internal waves by the interaction of an internal solitary wave with an underwater bank. J Geophys Res 110:C02019. doi:10.1029/2004JC002467 